\title{
Computational thermofluid-dynamic analysis of DEMO divertor cassette body cooling circuit
}

\author{
P. A. Di Maio ${ }^{\mathrm{a}^{*}}$, S. Garitta ${ }^{\mathrm{a}}$, J. H. You ${ }^{\mathrm{b}}$, G. Mazzone ${ }^{\mathrm{c}}$, M. Marino ${ }^{\mathrm{a}}$, E. Vallone ${ }^{\mathrm{a}}$ \\ ${ }^{a}$ University of Palermo, Viale delle Scienze, Edificio 6, 90128 Palermo, Italy \\ ${ }^{b}$ Max Planck Institute of Plasma Physics (E2M), Boltzmann Str.2, 85748 Garching, Germany \\ ${ }^{c}$ Department of Fusion and Technology for Nuclear Safety and Security, ENEA C.R. Frascati, via E. Fermi 45, 00044 \\ Frascati (Roma), Italy
}

\begin{abstract}
Within the framework of the Work Package Divertor, Subproject: Cassette Design and Integration (WPDIVCassette) of the EUROfusion action, a research campaign has been jointly carried out by ENEA and University of Palermo to investigate the thermal-hydraulic performances of the DEMO divertor cassette cooling system.

The research activity has been carried out following a theoretical-computational approach based on the finite volume method and adopting a qualified Computational Fluid-Dynamic (CFD) code.

Fully-coupled fluid-structure CFD analyses have been carried out for the recently-revised cassette body cooling circuit under nominal steady state conditions, imposing a non-uniform spatial distribution of nucleardeposited heat power volumetric density drawn from the most recent neutron transport analysis. The pertaining thermal-hydraulic performances have been assessed in terms of coolant flow velocity and total pressure distributions as well as of coolant and structure temperature distributions to check whether they comply with the corresponding prescribed limits. Results obtained are reported and critically discussed.
\end{abstract}

Keywords: DEMO, divertor, cassette body, CFD analysis, thermofluid-dynamics.

\section{Introduction}

The European Fusion Development Agreement roadmap was elaborated to pursue fusion as a sustainable, secure and commercial energy source [1]. In this framework, the divertor is a fundamental component of fusion power plants, being primarily responsible for power exhaust and impurity removal via guided plasma. Due to its position and functions, the divertor has to sustain very high heat and particle fluxes arising from the plasma (up to $20 \mathrm{MW} / \mathrm{m}^{2}$ ), while experiencing an intense nuclear deposited heat power, which could jeopardize its structure and limit its lifetime. Therefore, attention has to be paid to the thermal-hydraulic design of its cooling system, in order to ensure a uniform and proper cooling, without an unduly high pressure drop.

Within the framework of the activities foreseen by the Work Package Divertor, Subproject: Cassette Design and Integration (WPDIV-Cassette) of the EUROfusion action [2,3], a research campaign has been jointly carried out by University of Palermo and ENEA to investigate the steady state thermal-hydraulic performances of the DEMO divertor Cassette Body (CB) cooling circuit in view of its conceptual design.

During 2016, as a first step of the research campaign, a comparative evaluation study of the options under consideration for the CB coolant, namely sub-cooled pressurized water and helium, has been performed to check whether the considered cooling circuit lay-out might provide a uniform and effective cooling of the steel structure, suitable to maintain its temperature under the prescribed limit of $550^{\circ} \mathrm{C}$, without incurring in a unduly high pumping power. The first phase of the study, widely discussed in [4], has indicated that the reference concept of the CB cooling circuit (DC-I) is not suitable to match the target goal, since its structure temperature has been predicted to exceed the limit of $550^{\circ} \mathrm{C}$, no matter of the cooling option considered. During the second phase of the study, owing to the experience previously gained, the $\mathrm{CB}$ cooling circuit configuration has been revised issuing its DC-II concept, whose thermal-hydraulic performances have been numerically assessed assuming a preliminary uniform distribution of nuclear heating within both structure and flow domains. The results obtained, critically discussed in [4], have indicated that this revised concept shows significantly enhanced thermal-hydraulic performances for both the two cooling options considered, providing, in case of water cooling option (WCDC1) an acceptably uniform and effective cooling of the CB structure.

In October 2016, EUROfusion teams have agreed a revision of water-cooled CB cooling circuit thermalhydraulic operative conditions, mainly affecting coolant inlet/outlet temperatures and mass flow rate, and, more recently, a non-uniform spatial distribution of $\mathrm{CB}$ nuclear heating, calculated in presence of Dome, has been issued by the ENEA neutronic team. A second step of the research campaign has, hence, been launched to assess the thermal-hydraulic performances of the watercooled option of CB cooling circuit under the revised steady state nominal conditions.

A theoretical-numerical approach based on the finite volume method has been followed adopting the commercial Computational Fluid-Dynamic (CFD) code ANSYS CFX v.16.2, previously used in similar studies to evaluate concentrated hydraulic resistances to be used in system codes [5-7]. Analysis models and assumptions are herein reported and critically discussed, together with the main results obtained. 


\section{Cassette body thermal-hydraulic analysis}

According to its 2016 design, DEMO divertor is articulated in 54 toroidal cassettes, each composed of two Plasma Facing Components (PFCs), namely an inner and an outer vertical target, and a cassette body.

The CB is intended to support PFCs and shield Vacuum Vessel (VV) from irradiation. Therefore, in order to remove its nuclear deposited heat power, it is endowed with an active cooling circuit relying on the use of subcooled pressurized water at the inlet pressure and temperature of $3.5 \mathrm{MPa}$ and $180^{\circ} \mathrm{C}$, respectively, flowing with a thermal rise of $30^{\circ} \mathrm{C}$. The most recent layout of the water-cooled CB cooling circuit, taken into account for the present research campaign, results slightly revised with respect to the previously investigated DC-II concept and it is shown in Fig. 1.

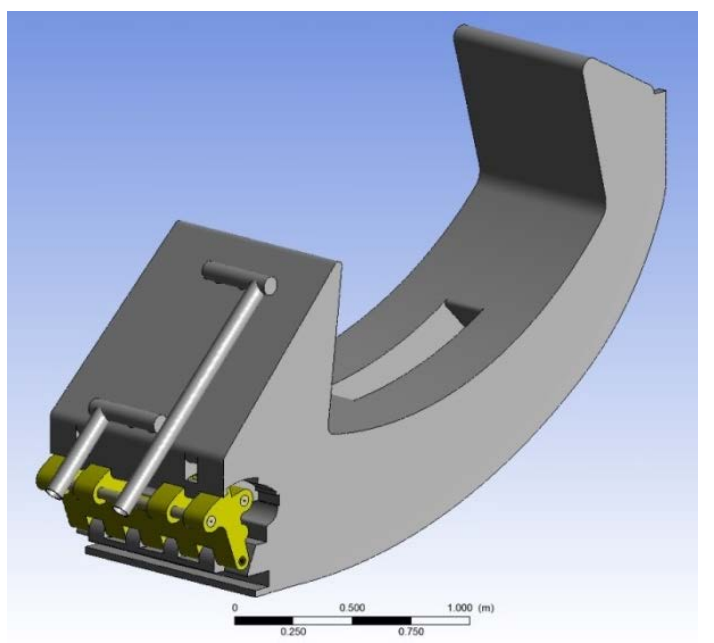

Fig. 1. DEMO divertor cassette body 2016 design.

\section{CB cooling circuit CFD analysis}

The thermal-hydraulic performances of the considered water-cooled CB cooling circuit have been assessed by running a steady state, fully coupled fluidstructure, thermofluid-dynamic analysis under the coolant operative conditions agreed in October 2016 with EUROfusion teams (Table 1).

Table 1 . Summary of coolant operative conditions.

\begin{tabular}{lc}
\hline & Conditions \\
\hline Inlet Pressure [MPa] & 3.5 \\
Inlet Temperature $\left[{ }^{\circ} \mathbf{C}\right.$ ] & 180 \\
$\Delta$ T $\left[{ }^{\circ} \mathbf{C}\right]$ & 30 \\
Removed Power [MW] & 115.2 \\
G per Cassette $[\mathrm{kg} / \mathbf{s}]$ & 15.94 \\
\hline
\end{tabular}

To this purpose, a sensitive analysis has been carried out to select the geometric discretization of fluid and structure domains allowing grid-independent results to be obtained saving calculation time.
Selected mesh parameters are reported in Table 2 and a detail of the mesh selected is shown in Fig. 2. Main assumptions, models and Boundary Conditions (BCs) adopted for the analysis are reported in Table 3.



Fig. 2. Detail of the mesh set-up for calculations.

Table 2. Summary of the main mesh parameters.

\begin{tabular}{llc}
\hline Region & \multicolumn{1}{c}{ Mesh Parameter } & Value \\
\hline \multirow{4}{*}{ Fluid } & Nodes & $3.5210^{+6}$ \\
& Elements & $8.8310^{+6}$ \\
& Inflation layers number & 12 \\
& First layer thickness $[\boldsymbol{\mu m}]$ & 200 \\
& Layers growth rate & 1.3 \\
& Typical Element Size [m] & $9.24 \cdot 10^{-3}$ \\
& Surface with y+ <150 [\%] & 96.2 \\
\hline \multirow{2}{*}{ Structure } & Nodes & $1.1510^{+6}$ \\
& Elements & $5.5410^{+6}$ \\
\hline
\end{tabular}

Table 3. Summary of assumptions, models, loads and BCs.

\begin{tabular}{lc}
\hline Analysis type & Steady state \\
& Water IAPWS IF97 \\
& EUROFER \\
Material library & Nickel Alumin. Bronze \\
& $316 \mathrm{~L}(\mathrm{~N})$ Steel \\
& Steel 660 \\
Nuclear heating & Non uniform (Fig. 3) \\
Radiative heat transfer & Towards VV @ 200 ${ }^{\circ} \mathrm{C}$ \\
Turbulence model & $\mathrm{k}-\varepsilon$ \\
Boundary layer modelling & $\mathrm{Scalable} \mathrm{wall} \mathrm{functions}$ \\
Wall roughness & $15 \mu \mathrm{m}$ \\
Inlet BC & $\mathrm{T}=180^{\circ} \mathrm{C} / \mathrm{ps}_{\mathrm{s}}=3.5 \mathrm{MPa}$ \\
Outlet BC & $\mathrm{G}=15.94 \mathrm{~kg} / \mathrm{s}$ \\
\hline
\end{tabular}

As far as nuclear heating data are concerned, the nonuniform distribution of nuclear-deposited heat power density calculated by ENEA neutronic team for a CB endowed with a Dome [8] has been properly scaled so to save the overall power deposited within the $\mathrm{CB}$ in absence of Dome, amounting to 115.2 MW (Fig. 3). 


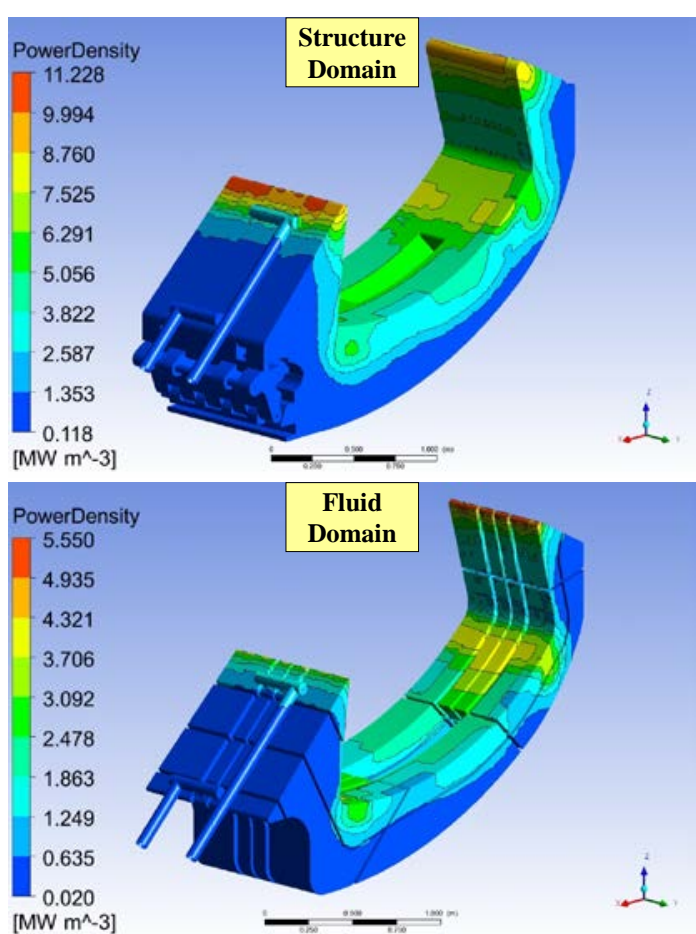

Fig. 3. Nuclear heating distribution adopted for calculations.

Moreover, the complex heat transfer process towards VV has been roughly simulated by means of a radiative heat transfer condition towards an heat sink, uniformly assumed at $200{ }^{\circ} \mathrm{C}$, applied over all the surfaces exposed to the $\mathrm{VV}$ and highlighted in yellow in Fig. 4. Further details on analysis and models may be found in [9].



Fig. 4. Radiative surfaces.

\subsection{Results}

A steady state, fully coupled fluid-structure, thermofluid-dynamic analysis of the considered watercooled CB cooling circuit has been carried out assessing its thermal-hydraulic performances in terms of:

- coolant flow velocity distribution;

- coolant total pressure distribution;

- coolant temperature distribution;

- CB structure temperature distribution.
Results obtained have allowed to check whether the investigated thermal-hydraulic performances comply with the corresponding limits, paying a particular attention to fluid and structure temperature fields. In fact, the fluid should not reach the saturation temperature to avoid the occurrence of bulk saturation in any part of its domain. Furthermore, the structure, made in EUROFER, should not exceed the temperature of $550{ }^{\circ} \mathrm{C}$.

Table 4 reports the main results obtained, summarizing the coolant thermal rise and total pressure drop between inlet and outlet sections (Fig 5), the total pumping power needed to route the coolant inside the CB cooling circuit and the maximum temperatures predicted for both the coolant and the steel structure.

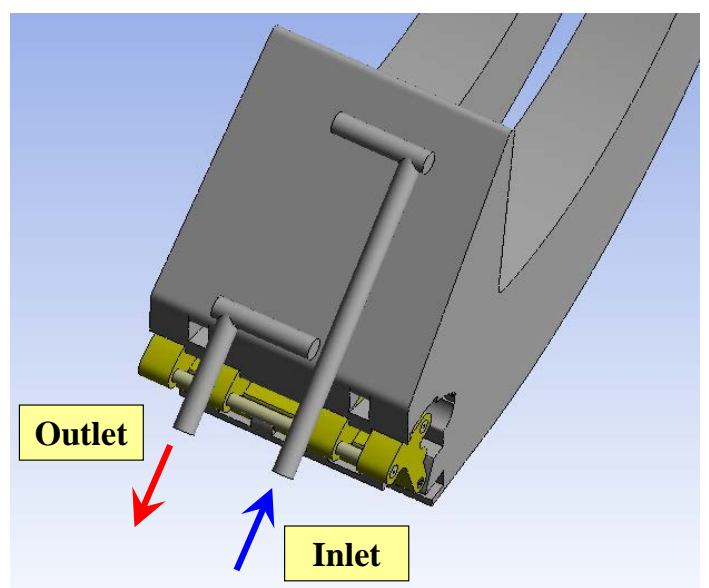

Fig. 5. Inlet and outlet sections.

Table 4. CB-DCI CFD analyses main results.

\begin{tabular}{lc}
\hline$\Delta \mathbf{p}$ [MPa] & 0.1047 \\
Pumping power [kW] & 1.930 \\
$\Delta \mathbf{T}$ fluid $\left[{ }^{\circ} \mathbf{C}\right]$ & 30.4 \\
$\mathbf{T}_{\max }$ fluid/structure $\left[{ }^{\circ} \mathbf{C}\right]$ & $619.9 / 955.9$ \\
\hline
\end{tabular}

As it may be deduced from the analysis of Table 4, the overall hydraulic performances of the CB cooling circuit result quite acceptable, its overall total pressure drop being slightly higher than $0.1 \mathrm{MPa}$ and the estimate pumping power resulting lower than $2 \mathrm{~kW}$ per cassette. Conversely, the heat removal aptitude of the same circuit shows some issues. In fact, even if the overall coolant thermal rise amounts to $30.4{ }^{\circ} \mathrm{C}$, letting the coolant to exit the circuit with a bulk temperature slightly higher than $210^{\circ} \mathrm{C}$, the coolant and the structure experience locally very high temperatures, suggesting the occurrence of local vaporization and thermal crisis.

As to the fluid domain, flow velocity total pressure and temperature distributions together with a detail of the most critical areas from the thermal standpoint are reported in Figs. 6-9. On the other hand, the structure thermal field distribution together with some significant details nearby its outer corner and attachment system region are reported in Figs. 10-13. 


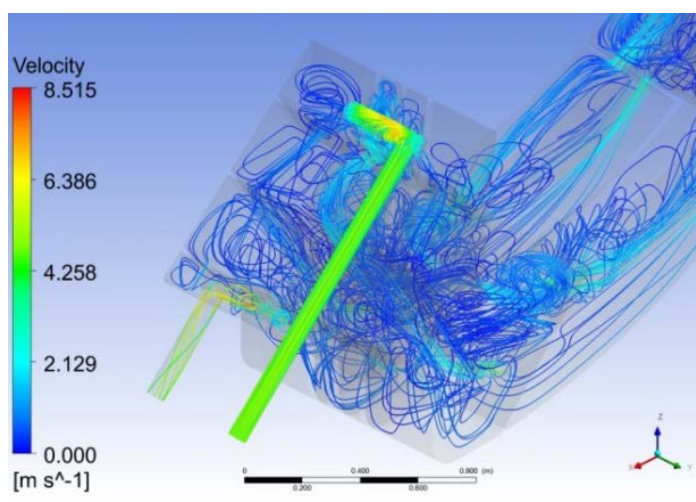

Fig. 6. Flow velocity field.

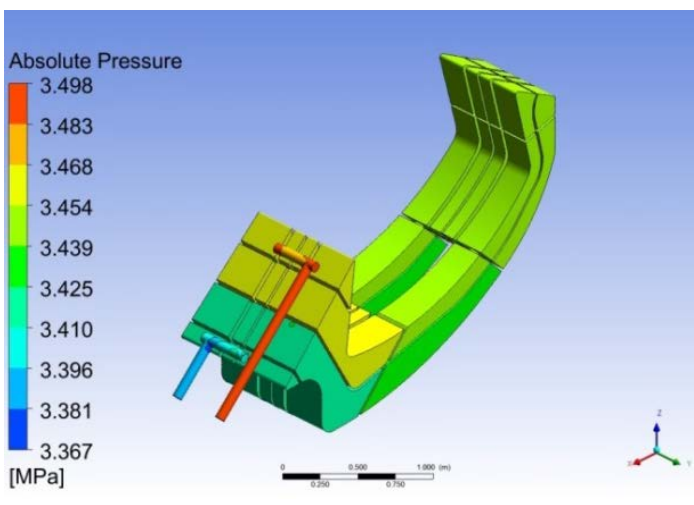

Fig. 7. Total pressure field.

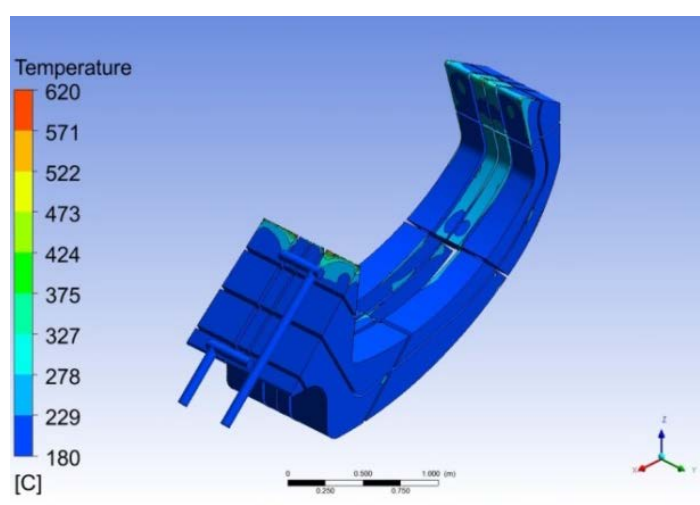

Fig. 8. Fluid temperature field.

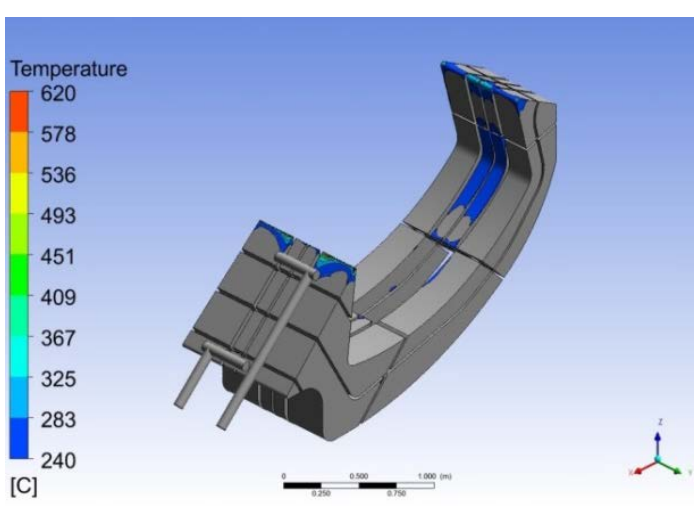

Fig. 9. Fluid critical areas.

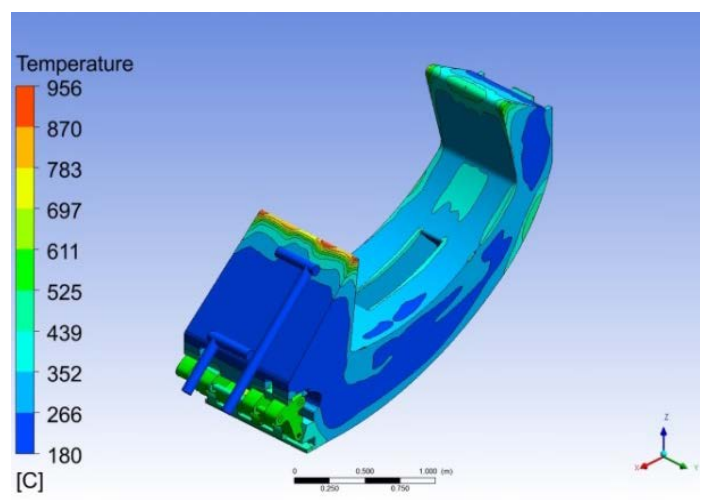

Fig. 10. Structure temperature field.

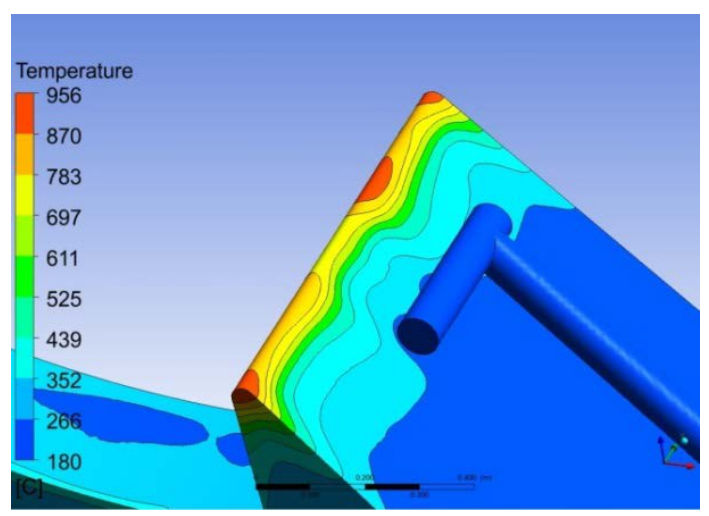

Fig. 11. Outer corner temperature field.

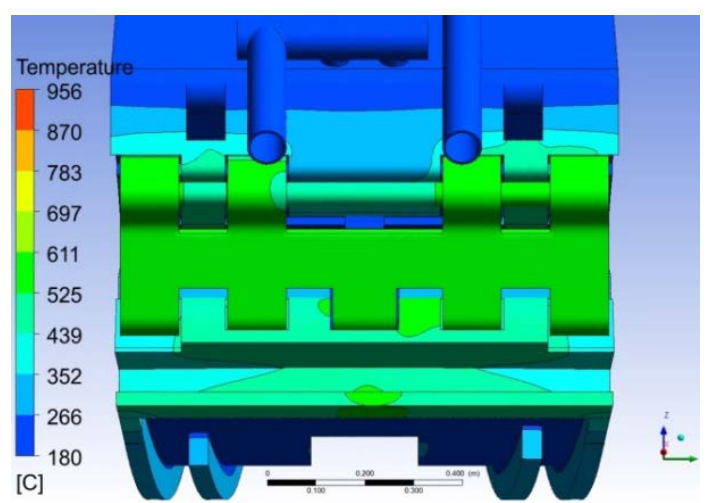

Fig. 12. Attachment system temperature field.



Fig. 13. CB poloidal-radial section temperature field. 
In particular, Fig. 9 refers to the fluid critical areas, defined as those regions where the fluid temperature exceeds the saturation value, conservatively calculated at the minimum pressure reached inside the flow domain $\left(240.34{ }^{\circ} \mathrm{C}\right)$, and vaporization is, hence, predicted to occur. Even though the maximum temperature calculated $\left(619.9^{\circ} \mathrm{C}\right)$ is significantly higher than the saturation temperature, predicted critical areas are extremely localized mainly at the interface fluid/walls of cassette corners, encouraging to solve their issue by further improving the cooling circuit layout and/or the coolant operative conditions. Similarly, as to the structure, Figs. 10 and 11 exhibit wide critical areas where the temperature is predicted to be higher than the limit of $550{ }^{\circ} \mathrm{C}$, mainly nearby the cassette outer corner (Fig. 13). In addition, as outlined in Fig. 12, the attachment system as well, mainly made of nickel aluminium bronze alloy, reaches significantly high temperatures $\left(616.2^{\circ} \mathrm{C}\right)$ suggesting the need for the further revision of its design.

Anyway, a further investigation is strongly suggested for the CB thermal-hydraulic performances based on a more detailed and reliable assessment of nuclear heating distribution, since it plays a pivotal role in the localization and intensity of thermal peaks predicted inside the structure.

\section{Conclusions}

Within the framework of the activities foreseen in the WPDIV-Cassette of the EUROfusion action, a research campaign has been carried out at the University of Palermo, in cooperation with ENEA, to investigate the steady state thermal-hydraulic performances of the divertor $\mathrm{CB}$ cooling circuit, focussing the attention on the latest design of its water cooled option and assuming the coolant operative conditions agreed in October 2016.

A theoretical-computational approach based on the Finite Volume Method has been followed and a commercial CFD code has been adopted to run a steady state, fully coupled fluid-structure, thermofluid-dynamic analysis of the considered CB cooling circuit under the assumed operative coolant conditions.

Results obtained have indicated that the CB cooling circuit seems to be able to provide a sufficiently uniform and effective cooling to the main part of the cassette steel structure without incurring in unduly high coolant pressure drop ( $\sim .1 \mathrm{MPa})$ and pumping power $(\sim 2 \mathrm{~kW}$ per cassette). Anyway, some small regions have been observed, mainly located nearby the cassette outer corner, where the predicted cooling circuit thermalhydraulic performances do not match the requirements of safety and operation temperature limits. In this critical areas the fluid experiences vaporization at the interface with steel walls and the structure exceeds the limit temperature of $550{ }^{\circ} \mathrm{C}$, reaching a maximum of $956{ }^{\circ} \mathrm{C}$. A further slight revision of the flow path and/or the coolant operative conditions is, hence, suggested in order to reach more effective cooling, particularly at the outer CB corner.

\section{Acknowledgments}

This work has been carried out within the framework of the EUROfusion Consortium and has received funding from the Euratom research and training programme 2014-2018 under grant agreement No 633053. The views and opinions expressed herein do not necessarily reflect those of the European Commission.

\section{References}

[1] F. Romanelli et al., Fusion Electricity - A Roadmap to the Realisation of Fusion Energy, European Fusion Development Agreement (EFDA), 2012, ISBN 978-3-00040720-8T.

[2] J.H. You et al., Conceptual design studies for the European DEMO divertor: Rationale and first results, Fusion Eng. Des. 109-111 (2016) 1598-1603, http://dx.doi.org/10.1016/j.fusengdes.2015.11.012.

[3] J.H. You, et al., Progress in the initial design activities for the European DEMO divertor: Subproject "Cassette", Fusion Eng. Des. (2017), http://dx.doi.org/10.1016/j.fusengdes.2017.03.01.

[4] P.A. Di Maio, S. Garitta, J. H. You, G. Mazzone, E. Vallone, Analysis of steady state thermal-hydraulic behaviour of the DEMO divertor cassette body cooling circuit, Fusion Engineering and Design (2017), http://dx.doi.org/10.1016/j.fusengdes.2017.02.025.

[5] P.A. Di Maio et al., Analysis of the steady state hydraulic behaviour of the ITER blanket cooling system, Fusion Eng. Des. 98-99 (2015) 1470-1473, http://dx.doi.org/10.1016/j.fusengdes.2015.05.070.

[6] P.A. Di Maio et al., Numerical simulation of the transient thermal-hydraulic behaviour of the ITER blanket cooling system under the draining operational procedure, Fusion Eng. Des. 98-99 (2015) 1664-1667, http://dx.doi.org/10.1016/j.fusengdes.2015.01.024.

[7] P.A. Di Maio et al., On the hydraulic behaviour of ITER Shield Blocks \#14 and \#08. Computational analysis and comparison with experimental tests, Fusion Eng. Des. 109-111 30-36, http://dx.doi.org/10.1016/j.fusengdes.2016.03.060.

[8] R. Villari, peronal communications.

[9] Final Report on Deliverable DEMO Divertor - Thermohydraulic assessment report 2016, Report IDM reference No EFDA_D_2MMTTU, DIV-1-T002-D006. 